\title{
The passage from a particle system to a continuum model
}

\author{
R. S. RIVLIN (BETHLEEM)
}

A THREE-DIMENSIONAL lattice is considered in which each cell contains a number of mass-points. These mass-points undergo displacements under the action of forces. It is shown how, under appropriate smoothness assumptions regarding the forces and displacements, as we move from mass-point to corresponding mass-point in neighboring cells, a continuum model of the director type can be formulated for the mechanical behavior of the system. Particular attention is given to the identification of the "surface" of the system.

W pracy omówiono trzy metody, które są zwykle wykorzystywane przy wyprowadzeniu równań ruchu dla punktu i warunków brzegowych mechaniki uogólnionego kontinuum oraz dla przypadku, gdy deformacja opisana jest przez inne niż zwykłe pole przemieszczenia lub pola dodatkowe. Są to metody wykorzystujące zastosowanie globalnych równań bilansu energii lub uogólnionej zasady d'Alemberta oraz równań pędu i momentu pędu. W dyskusji nacisk położono na te aspekty analizy, które wynikają z rozważań o charakterze ogólnym oraz takie, które bezpośrednio lub pośrednio narzucają pewne założenia na fizykalną naturę przyjmowanych $w$ teorii zmiennych kinematycznych. Wyciągnięto wniosek, że dla większości przypadków te teorie, w których zmienne kinematyczne nie mają bezpośredniego znaczenia odpowiadającego właściwemu układowi fizycznemu lub klasie układów fizycznych, mają bardzo ograniczoną wartość. Przedyskutowano zatem kilka dopuszczalnie wyidealizowanych prostych układów $\mathrm{z}$ punktu widzenia różnych typów zmiennych kinematycznych, które mogą mieć zastosowanie do opisu deformacji i narzucają ograniczenia na naturę tych zmiennych implikowaną przez opisany układ fizyczny. Wreszcie przeprowadzono próbę zanalizowania ograniczeń nałożonych na mechaniczne teorie uogólnionego kontinuum w ten sam sposób, w jaki dokonano przejścia od opisu układu wyrażonego w wielkościach określonych w dyskretnych punktach obszaru zajmowanego przez rozważane ciało do opisu, w którym wielkości te są zastąpione przez pola określone na tym obszarze.

В работе обсуждены три метода, которые обычно используются при выводе уравнений движения для точки и граничных условий механики обобщеңного континуум, где деформация описывается через другое, чем обычно, поле перемещений или через дополнительңые поля. Это методы базирующие на применении глобальных уравнений балаңса энергии, или на расширении принципа Даламбера, а также уравнений импульса и момента импульса. В обсуждении обращено внимание на эти аспекты анализа, которые вытекают из рассуждений общего характера и на те, которые непосредственно или посредственным образом ңакладывают некоторые предположения на физическую природу принимаемых в теории кинематических переменных. Сделан вывод, что для большинства случаев эти теории, в которых кинематические переменные не имеют непосредственного значения, отвечающего свойственной физической системе или классу физических систем, имеют очеңь ограниченное значеңие. Итак обсудим несколько допустимо идеализированных простых систем с точки зрения разньг типов кинематических перемеңных, которые могут иметь применение для описания деформаций и накладывают ограничения на природу этих перемеңньг, вызванную через описанную физическую систему. Наконец предпринята попытка анализа ограңичений наложеңных на мехаңические теории обобщенного континуум таким самым образом, как проведен переход от описания системы, выраженной в величиңах определеңных в дискретных точках области заңимаемой через рассматриваемое тело, к описанию, в котором эти величины замеңеңы полями определенными в этой области,

\section{Introduction}

IN recent years many continuum-mechanical theories have been formulated in which the deformation is described by one or more vector or tensor fields in addition to the usual 
displacement field. A succinct historical review of the differences between some of these theories is given in the introduction of a paper by TIERSTEN and BLEUSTEIN [1]. In some cases, the theory is presented on the basis of certain assumptions of a mathematical nature, which may perhaps be regarded as axioms of the theory. Beyond a vague statement that the continuum theory is intended to model media which have some structure, the system which the theory models is ill-defined. Also, little, or no, indication is given of the relation between the variables of the continuum theory and those of the physical system modelled.

In 1964, GREeN and RIVLIN [2] presented a thermomechanical theory in which the deformation field in a body was described by a number of tensors of various orders, in addition to a conventional displacement field. While their theory was motivated heuristically by a physical model consisting of interacting "particles", each of which consists of a number of mass-points, the passage from the particle model to the continuum theory was not made explicit. In later papers, GREen and RIVLIN [3] and RIVLIN [4, 5] attempted to achieve this passage with increasing degrees of explicitness. While none of these papers presents a completely satisfactory procedure for making the transition from particle model to continuum theory, certain points that are worth noting emerge.

It appears that in order to obtain a continuum model of the particle system, it is necessary that the displacements undergone by corresponding mass-points in different particles vary sufficiently slowly as we move from particle to neighboring particle. It was argued by RIVLIN [5] that this indicates that the generalized continuum theories which model the particle system cannot be applied to problems in which the applied forces may vary rapidly on the scale of the structure. (It has been argued that the results of the generalized continuum theories could be given meaning, in such cases, as predictive of ensemble averages. However, such ensemble averages would, at any rate in the case of linear theories, be equivalent to the solution of problems in which the applied forces do not vary rapidly on the scale of the structure.)

It appeared also, from the discussion in $[4,5]$, that continuum theories which are formally very different can model the same system and that unless the various fields introduced in a continuum theory are clearly identified with variables describing the behavior of the particle system, which it pretends to model, the theory remains empty of physical significance.

The present paper takes up again this question of the passage from a particle system to a continuum model. It differs from the previous papers in a number of ways. In order to concentrate on other aspects of the problem, the implications which are inherent in the consideration of the dynamical case (see, e.g., [5]) are avoided by considering only quasistatic thermomechanical processes. Also, the physical model considered is a threedimensional lattice, each cell of which contains a number of mass-points. (In contrast, the composite particles considered in $[3,4,5]$ are geometrically related in an unspecified manner.) This enables us to be much more explicit in underlining the difficulties associated with the passage from particle system to continuum model and particularly with the identification, in the particle system, of the surface of the body in the continuum model. It is not maintained that the identification achieved here is completely satisfactory and it is perhaps not possible to achieve such identification without some heuristic elements remaining. 


\section{Generalized coordinates and forces}

In classical continuum-mechanical theories, it is considered that the deformation of a body is fully described if the vector position $\mathbf{x}$ at time $t$ of a generic particle of the body, with respect to a fixed origin, is specified as a function of its vector position $\mathbf{X}$ at some reference time.

In generalized continuum-mechanical theories we consider that, in order to describe the deformation fully, we must specify, not only the dependence of $\mathbf{x}$ on $\mathbf{X}$ and $t$, but also the dependence of $\mu$ other variables $\xi_{\alpha}(\alpha=1, \ldots, \mu)$ on $\mathbf{X}$ and $t$. The quantities $\xi_{\alpha}$ may be scalars or the components in some coordinate system of vectors or tensors. We shall call $\xi_{\alpha}$ the generalized displacements of the particle.

Again, in the Piola-Kirchhoff formulation of classical continuum mechanics, we consider that the force system acting on a body of the material considered consists of body forces $\mathbf{f}$ per unit mass and surface forces $F$, per unit surface area measured in the reference configuration of the body. The power $\mathscr{P}$ of these forces is given by

$$
\mathscr{P}=\int_{V} \varrho \mathbf{f} \cdot \dot{\mathbf{x}} d V+\int_{S} \mathbf{F} \cdot \dot{\mathbf{x}} d S,
$$

where $\varrho$ is the material density in the reference configuration, $V$ is the domain occupied by the body in its reference configuration, and $S$ is the surface of this domain.

In the generalized continuum-mechanical theories, the force system acting on the body consists not only of the force fields $\mathbf{f}$ and $\mathbf{F}$, but of further force fields conjugate to the generalized displacements $\xi_{\alpha}$. It is assumed that the power $\mathscr{P}$ of the forces acting on the body is given by

$$
\mathscr{P}=\int_{V} \varrho \mathbf{f} \cdot \dot{\mathbf{x}} d V+\int_{S} \mathbf{F} \cdot \dot{\mathbf{x}} d S+\Sigma \int_{V} \varrho \phi_{\alpha} \dot{\xi}_{\alpha} d V+\Sigma \int_{S} \Phi_{\alpha} \dot{\xi}_{\alpha} d S .
$$

$\Sigma$ denotes summation over $\alpha=1,2, \ldots, \mu$. The forces $\phi_{\alpha}$ are the generalized body forces and the forces $\Phi_{\alpha}$ are the generalized surface forces.

\section{The energy balance}

In the energy balance approach to the derivation of the point equations, it is assumed that thermal energy is supplied to the body in addition to the energy supplied by the work of the conventional and generalized forces. We assume that the heat supply takes place through the surface of the body at a rate $Q$, per unit area measured in the reference configuration, and throughout the volume of the body at a rate $q$, per unit mass. The rate $\mathscr{Q}$ at which heat is supplied to the body is thus given by

$$
\mathscr{Q}=\int_{V} \varrho q d V+\int_{S} Q d S
$$

It follows from the First Law of Thermodynamics that

$$
\mathscr{P}+\mathscr{2}=\dot{\mathscr{U}}+\dot{\mathscr{T}},
$$

where $\mathscr{U}$ is the internal energy of the body and $\mathscr{T}$ is its kinetic energy. 
We assume that the forces exerted by one part of the body on another are short-range forces, so that the internal energy is additive and may, accordingly, be expressed in the form

$$
\mathscr{U}=\int_{V} \varrho \varepsilon d V+\int_{S} E d S .
$$

We shall, for the moment, consider only quasistatic deformations, so that $\dot{T}=0$ in (3.2). The various rates in the equations developed may be considered to be measured with respect to a time-like variable, rather than with respect to real time. An appropriate time-like variable results from any sufficiently smooth monotonic mapping which maps an infinite interval of real time onto a finite interval. Alternatively, we could replace the rates, in the various equations, by infinitesimal variations. In the interests of succinctness, we shall adopt the former course. Also, we shall assume that effects arising from surface tension are negligible, so that in (3.3) we may take $E=0$.

With $\dot{\mathscr{T}}=0$ and $\mathscr{P}, \mathscr{Q}$ and $\mathscr{U}$ given by (2.2), (3.1) and (3.3) respectively, we obtain, from (3.2), with $\dot{E}=0$,

$$
\begin{aligned}
\int_{V} \varrho \dot{\varepsilon} d V=\int_{V} \varrho \mathbf{f} \cdot \dot{\mathbf{x}} d V+\int_{S} \mathbf{F} \cdot \dot{\mathbf{x}} d S & \\
& +\sum \int_{V} \varrho \phi_{\alpha} \dot{\xi}_{\alpha} d V+\sum \int_{S} \Phi_{\alpha} \dot{\xi}_{\alpha} d S+\int_{V} \varrho q d V+\int_{S} Q d S .
\end{aligned}
$$

This is the global equation of energy balance for quasistatic deformations of the body considered. Our object is to obtain from it point equations.

We assume that the forces exerted by one portion of the body on another in contact with it are of the same types as the applied surface forces considered, so that equation (3.4) may be applied to any portion of the body, if appropriate interpretation is given to $V, S$ and to the forces $\mathbf{f}, \mathbf{F}, \phi_{\alpha}, \Phi_{\alpha}$. We shall apply it to an infinitesimal tetrahedral element of the body which, in the reference configuration, has edges parallel to the axes of a rectangular cartesian coordinate system $x$ and slant surface with unit outward normal $\mathbf{N}$. We denote the ordinary force exerted at "time" $t$ on the slant surface by $\mathbf{F}$ and on that initially perpendicular to the axis $x_{\boldsymbol{A}}$ by $\mathbf{F}_{\boldsymbol{A}}$. Similarly, we denote the generalized force, conjugate to the generalized displacement $\xi_{\alpha}$, acting on the slant surface by $\Phi_{\alpha}$ and that acting on the surface initially normal to the axis $x_{A}$ by $\Phi_{\alpha A}$. Both the ordinary forces and the generalized forces are measured per unit area of surface in the reference configuration. We also denote the rate at which heat flows into the tetrahedral element at "time" $t$ through the slant surface by $Q$ and the rate at which it flows through the surface initially perpendicular to $x_{A}$ by $Q_{A}$. Again, the rates are measured per unit area in the reference configuration. It then follows from (3.4), in the limit as the tetrahedral element becomes vanishingly small, that $\left({ }^{1}\right)$

$$
\left(\mathbf{F}-\mathbf{F}_{A} N_{A}\right) \cdot \dot{\mathbf{x}}+\sum\left(\Phi_{\alpha}-\Phi_{\alpha A} N_{A}\right) \dot{\xi}_{\alpha}+Q-Q_{A} N_{A}=0 .
$$

This relation is valid at each point of the body. We can accordingly use it to substitute for $\left(\mathbf{F} \cdot \dot{\mathbf{x}}+\sum \Phi_{\alpha} \dot{\xi}_{\alpha}+Q\right)$ in (3.4). We thus obtain, on using the divergence theorem to

( $\left.{ }^{1}\right)$ The Einstein summation convention is adopted for upper and lower case Latin subscripts. 
replace surface integrals by volume integrals, and applying the result to an infinitesimal element,

$$
\varrho \dot{\varepsilon}=\left(\varrho \mathbf{f}+\mathbf{F}_{A, A}\right) \cdot \dot{\mathbf{x}}+\sum\left(\varrho \phi_{\alpha}+\Phi_{\alpha A, A}\right) \dot{\xi}_{\alpha}+\left(\varrho q+Q_{A, A}\right)+\mathbf{F}_{A} \cdot \dot{\mathbf{x}}_{, A}+\sum \Phi_{\alpha A} \dot{\xi}_{\alpha, A} .
$$

We can proceed no further without making some assumption regarding the manner in which the various quantities involved are affected by a superposed rigid motion. Plainly, $q, Q$ and $\varepsilon$ are unaltered by such a superposed motion. The superposition of a translation $\mathbf{u}$, say, on the assumed deformation changes $\dot{\mathbf{x}}$ to $\dot{\mathbf{x}}+\dot{\mathbf{u}}$, while leaving $\mathbf{f}, \mathbf{F}$, $\mathbf{F}_{A}, Q_{A}$, and $\dot{\mathbf{x}}_{\cdot A}$, unchanged. We shall assume, in the present paper, that the $\mu$ variables $\xi_{\alpha}$ are the components $\xi_{i}^{(\beta)}$ in a rectangular Cartesian system $x$ of $\nu=\frac{1}{3} \mu$ vectors $\xi_{\beta}$ $(\beta=1, \ldots, v)$. These vectors are called directors. Correspondingly, the generalized forces $\phi_{\alpha}$ and $\Phi_{\alpha}$ are the components $\phi_{i}^{(\beta)}$ and $\Phi_{i}^{(\beta)}$ of $v$ vectors $\phi_{\beta}$ and $v$ vectors $\Phi_{\beta}(\beta=1, \ldots, v)$ respectively. It follows from the definition of $\Phi_{\alpha A}$ that these are the components $\Phi_{A i}^{(\beta)}$ in the system $x$ of $3 v$ vectors $\boldsymbol{\Phi}_{\beta A}$, say. We shall assume that the vectors $\xi_{\beta}, \phi_{\beta}, \boldsymbol{\Phi}_{\beta}$ - and therefore $\boldsymbol{\Phi}_{\beta A}$ - are material vectors, so that if the body considered is subjected to a rigid rotation such that the particle at $\mathbf{x}$ moves to $\mathbf{a x}$, where $\mathbf{a}$ is a proper orthogonal transformation, $\xi_{\beta}, \phi_{\beta}, \boldsymbol{\Phi}_{\beta}$ and $\boldsymbol{\Phi}_{\beta A}$ change to $\mathbf{a} \mathbf{F}_{\beta}, \mathbf{a} \phi_{\beta}, \mathbf{a} \boldsymbol{\Phi}_{\beta}$ and $\mathbf{a} \boldsymbol{\Phi}_{\beta \lambda}$ respectively. We shall further assume that the superposition of a translation $\mathbf{u}$ on the assumed deformation leaves $\xi_{\beta}$ and the generalized forces conjugate to $\xi_{\beta}$ unchanged. The forces $\phi_{\beta}$ and $\boldsymbol{\Phi}_{\beta}$ are called director body forces and director surface forces respectively.

With this choice of the generalized displacements, we can rewrite (3.6) as

$$
\varrho \dot{\varepsilon}=\left(\varrho f_{i}+F_{A i, A}\right) \dot{x}_{i}+\sum\left(\varrho \phi_{i}^{(\beta)}+\Phi_{A i, A}^{(\beta)}\right) \dot{\xi}_{i}^{(\beta)}+\varrho q+Q_{A, A}+F_{A i} \dot{x}_{i, A}+\sum \Phi_{A i}^{(\beta)} \dot{\xi}_{i, A}^{(\beta)},
$$

where $x_{i}, \xi_{i}^{(\beta)}, F_{A i}, \ldots$, denote the components in the rectangular Cartesian system $x$ of the vectors $\mathbf{x}, \boldsymbol{\xi}_{\beta}, \mathbf{F}_{A}, \ldots$. Here and subsequently, $\sum$ denotes summation over $\beta=$ $=1, \ldots, v$.

Similarly, we can re-write (3.5) as

$$
\left(F_{i}-F_{A i} N_{A}\right) \dot{x}_{i}+\sum\left(\Phi_{i}^{(\beta)}-\Phi_{A i}^{(\beta)} N_{A}\right) \dot{\xi}^{(\beta)}+Q-Q_{A} N_{A}=0 .
$$

If a translation $\mathbf{u}$, with components $u_{i}$ in the system $x$, is superposed on the assumed deformation, then (3.7) becomes

$$
\varrho \dot{\varepsilon}=\left(\varrho f_{i}+F_{A i, A}\right)\left(\dot{x}+\dot{u}_{i}\right)+\sum\left(\varrho \phi^{(\beta)}+\Phi_{A l, A}^{(\beta)}\right) \dot{\xi}^{(\beta)}
$$

$$
+\varrho q+Q_{A, A}+F_{A i} \dot{x}_{i, A}+\sum \Phi_{A l}^{(\beta)} \dot{\xi}_{A, i}^{(\beta)} .
$$

From (3.7) and (3.9), we have

$$
\varrho f_{i}+F_{A i, A}=0
$$

and

$$
\varrho \dot{\varepsilon}=\sum\left(\varrho \phi l^{(\beta)}+\Phi_{A l, A}^{(\beta)}\right) \dot{\xi}^{(\beta)}+\varrho q+Q_{A, A}+F_{A i} \dot{x}_{i, A}+\sum \Phi_{A i}^{(\beta)} \dot{\xi}(\beta),
$$

In a similar manner, we find from (3.8) that

$$
F_{i}-F_{A i} N_{A}=0
$$


and

$$
\sum\left(\Phi_{i}^{(\beta)}-\Phi_{A}^{(\beta)} N_{A}\right) \dot{\xi}^{(\beta)}+Q-Q_{A} N_{A}=0 .
$$

We now superpose on the assumed deformation an arbitrary rigid angular velocity, leaving the instantaneous configuration of the body unchanged. For the resulting deformation, equations $(3.10)_{2}$ and $(3.11)_{2}$ become respectively

$$
\begin{aligned}
\varrho \dot{\varepsilon}=\sum\left(\varrho \phi^{(\beta)}+\Phi_{A i, A}^{(\beta)}\right)\left(\dot{\xi}_{i}^{(\beta)}+\Omega_{i j} \xi_{j}^{(\beta)}\right) & +\varrho q+Q_{A, A} \\
& +F_{A i}\left(\dot{x}_{i, A}+\Omega_{i j} x_{j, A}\right)+\sum \Phi_{A i}^{(\beta)}\left(\dot{\xi}_{i, A}^{(\beta)}+\Omega_{i j} \xi_{j, A}^{(\beta)}\right)
\end{aligned}
$$

and

$$
\sum^{\prime}\left(\Phi_{(j)}^{(\beta)}-\Phi_{A l}^{(\beta)} N_{A}\right)\left(\dot{\xi}_{i}^{(\beta)}+\Omega_{i j} \xi^{(\beta)}\right)+Q-Q_{A} N_{A}=0,
$$

where $\left\|\Omega_{i}\right\|$ is an arbitrary constant skew-symmetric matrix. Equations $(3.10)_{1}$ and $(3.11)_{1}$ remain unchanged.

From equations (3.12), $(3.10)_{2}$ and $(3.11)_{2}$ we obtain

$$
\Omega_{i j}\left\{\sum\left(\varrho \phi^{(\beta)}+\Phi_{A l, A}^{(\beta)}\right) \xi^{(\beta)}+F_{A i} x_{j, A}+\sum \Phi_{A i}^{(\beta)} \xi_{j, A}^{(\beta)}\right\}=0
$$

and

$$
\Omega_{i j} \sum\left(\Phi_{i}^{(\beta)}-\Phi_{\lambda\left(N_{A}^{(\beta)}\right.} \dot{\xi}_{j}^{(\beta)}=0 .\right.
$$

The relations (3.13) are, of course, equivalent to

$$
\begin{aligned}
\sum\left(\varrho \phi_{i}^{(\beta)}+\Phi_{A, A}^{(\beta)}\right) \xi^{(\beta)}+F_{A i} x_{j, A}+ & \sum \Phi_{A i}^{(\beta)} \xi_{j, A}^{(\beta)} \\
& =\sum\left(\varrho \phi_{j}^{(\beta)}+\Phi_{A j, A}^{(\beta)}\right) \xi^{(\beta)}+F_{A j} x_{i, \Lambda}+\sum \Phi_{A j}^{(\beta)} \xi_{l, \lambda}^{(\beta)}
\end{aligned}
$$

and

$$
\sum\left(\Phi^{(\beta)}-\Phi_{A l}^{(\beta)} N_{A}\right) \xi^{(\beta)}=\sum\left(\Phi_{j}^{(\beta)}-\Phi_{A j}^{(\beta)} N_{A}\right) \xi^{(\beta)}
$$

\section{Elastic materials}

For simplicity we consider only isothermal, homothermal, thermomechanical processes. We consider the class of elastic materials in which, for such processes, in (3.7), the specific internal energy $\varepsilon$, the ordinary forces $F_{A i}$ and the generalized forces $\Phi_{A i}^{(\beta)}$ depend only on the deformation gradients $x_{j, B}$ and on the generalized displacements $\xi^{(\beta)}$ and their first spatial derivatives $\xi_{j, B}^{(\beta)}$, thus:

$$
\begin{aligned}
\varepsilon & =\varepsilon\left(x_{j, B}, \xi_{j}^{(\beta)}, \xi_{, B}^{(\beta)}\right), \\
F_{A i} & =F_{A i}\left(x_{j, B}, \xi_{j}^{(\beta)}, \xi_{j, B}^{(\beta)}\right), \\
\Phi_{A l}^{(\gamma)} & =\Phi_{A l}^{(\gamma)}\left(x_{j, B}, \xi_{j}^{(\beta)}, \xi_{j, B}^{(\beta)}\right) .
\end{aligned}
$$


Now, for isothermal, homothermal processes in an elastic material, we can define the specific entropy $\eta$ by the relation

$$
\dot{\eta}=q / T,
$$

where $T$ is the absolute temperature and $\eta$ is a function of $x_{j, B}, \xi_{j}^{(\beta)}$ and $\xi_{j, B}^{(\beta)}$ only; i.e.

$$
\eta=\eta\left(x_{j, B}, \xi^{(\beta)}, \xi_{j, B}^{(\beta)}\right) \text {. }
$$

We note that for such processes $Q_{A}=0$. Introducing (4.2) and $Q_{A}=0$ into $(3.10)_{2}$, we obtain

$$
\varrho \dot{w}=\sum\left(\varrho \phi_{i}^{(\beta)}+\Phi_{A i, A}^{(\beta)}\right) \dot{\xi}_{i}^{(\beta)}+F_{A i} \dot{x}_{i, A}+\sum \Phi_{\mu i}^{(\beta)} \dot{\xi}_{i, A}^{(\beta)},
$$

where $w$ is the specific Helmholtz free energy defined by

$$
w=\varepsilon-T \eta .
$$

From $(4.1)_{1},(4.3)$ and (4.5), we see that for isothermal, homothermal processes,

$$
w=w\left(x_{i, A}, \xi_{i}^{(\beta)}, \xi_{i, B}^{(\beta)}\right),
$$

so that

$$
\dot{w}=\frac{\partial w}{\partial x_{i, \Lambda}} \dot{x}_{i, \Lambda}+\sum\left\{\frac{\partial w}{\partial \xi_{i}^{(\beta)}} \dot{\xi}_{i}^{(\beta)}+\frac{\partial w}{\partial \xi_{i, \Lambda}^{(\beta)}} \dot{\xi}_{i, \Lambda}^{(\beta)}\right\} .
$$

From (4.4) and (4.7), we have

$$
\begin{aligned}
\left(F_{A i}-\varrho \frac{\partial w}{\partial x_{i, A}}\right) \dot{x}_{i, A}+\sum\left(\varrho \phi_{i}^{(\beta)}+\Phi_{A i, A}^{(\beta)}-\varrho \frac{\partial w}{\partial \xi^{(\beta)}}\right) \dot{\xi}_{i}^{(\beta)} & \\
& +\sum\left(\Phi_{A i}^{(\beta)}-\varrho \frac{\partial w}{\partial \xi_{i, A}^{(\beta)}}\right) \dot{\xi}_{i, A}^{(\beta)}=0 .
\end{aligned}
$$

We note from (4.1) and (4.3) that, for isothermal processes, the coefficients of $\dot{x}_{i, A}$, $\dot{\xi}^{(\beta)}$ and $\dot{\xi}_{i, A}^{(\beta)}$ are independent of these quantities. Assuming that the latter quantities can be chosen independently, we obtain from (4.8)

$$
\varrho \phi_{i}^{(\beta)}+\Phi_{A l, A}^{(\beta)}=\varrho \frac{\partial w}{\partial \xi_{i}^{(\beta)}}, \quad F_{A i}=\varrho \frac{\partial w}{\partial x_{i, A}}, \quad \Phi_{A i}^{(\beta)}=\varrho \frac{\partial w}{\partial \xi_{(, A}^{(\beta)}} .
$$

We also have (cf. (3.10) $)_{1}$

$$
\varrho f_{i}+F_{A i, A}=0 .
$$

For reasons which will appear later, we will now consider the modification in these results which follows from the assumption that the directors $\xi_{\alpha}$ satisfy the constraint

$$
\sum \lambda_{\beta} \xi^{(\beta)}=0
$$

where the $\lambda$ 's are constants. We may use the Lagrange method of undetermined multipliers to remove the effect of this constraint, in passing from (4.4) and (4.7) to (4.9), by rewriting (4.4) as

$$
\varrho \dot{w}=\sum\left(\varrho \phi_{i}^{(\beta)}+\Phi_{A i, A}^{(\beta)}\right) \dot{\xi}_{i}^{(\beta)}+F_{A i} \dot{x}_{i, A}+\sum \Phi_{A i}^{(\beta)} \dot{\xi}_{i, A}^{(\beta)}+\chi_{i} \sum \lambda_{\beta} \dot{\xi}_{i}^{(\beta)}+\zeta_{A i} \sum \lambda_{\beta} \dot{\xi}_{i, A}^{(\beta)},
$$


where $\chi_{i}$ and $\zeta_{A i}$ are the components of arbitrary undetermined tensors of first and second-order respectively. It then follows from (4.12) that

$$
\begin{gathered}
\varrho \phi^{(\beta)}+\Phi_{A i, A}^{(\beta)}=\varrho \frac{\partial w}{\partial \xi^{(\beta)}}+\chi_{i} \lambda_{\beta}, \\
F_{A i}=\varrho \frac{\partial w}{\partial x_{i, A}}, \quad \Phi_{A i}^{(\beta)}=\varrho \frac{\partial w}{\partial \xi_{i, A}^{(\beta)}}+\zeta_{A i} \lambda_{\beta} .
\end{gathered}
$$

\section{A physical model}

We consider the domain $\bar{V}$ to be occupied by a three-dimensional lattice consisting of $N$ identical cells. Each cell consists of $v$ mass-points with masses $m_{\beta}(\beta=1, \ldots, v)$, which interact with each other and with the mass points in the other cells. The mass $m$ of a cell is given by

$$
m=\sum m_{\beta},
$$

where $\sum$ denotes summation over $\beta=1, \ldots, v$.

Each mass-point is in Brownian motion about some ambient position. Let $\mathbf{X}_{\beta}^{(P)}$ be the ambient vector position, with respect to a fixed origin, of the $\beta$ th. mass-point of the $P$ th. cell. Let $\mathbf{X}^{(P)}$ be that of the center of mass of the $P$ th. cell. Then,

$$
m \mathbf{X}^{(P)}=\sum m_{\beta} \mathbf{X}_{\beta}^{(P)} .
$$

We write

$$
\Xi_{\beta}^{(P)}=\mathbf{X}_{\beta}^{(P)}-\mathbf{X}^{(P)} .
$$

Then

$$
\sum m_{\beta} \Xi_{\beta}^{(P)}=0 .
$$

We now assume that forces are applied to the various mass-points. Let the force applied to the $\beta$ th. mass-point of the $P$ th. cell be $m_{\beta} \mathbf{f}_{\beta}^{(P)}$. As a result of the application of these forces, the ambient vector position, with respect to the fixed origin, of this masspoint is $\mathbf{x}_{\beta}^{(P)}$ and that of the center of mass of the $P$ th. cell is $\mathbf{x}^{(P)}$. Then

$$
m \mathbf{x}^{(P)}=\sum m_{\beta} \mathbf{x}_{\beta}^{(P)} .
$$

We write

$$
\xi_{\beta}^{(P)}=\mathbf{x}_{\beta}^{(P)}-\mathbf{x}^{(P)} .
$$

Then,

$$
\sum m_{\beta} \xi_{\beta}^{(P)}=0 .
$$

The power $\mathscr{P}$ of the applied forces acting on the $N$ cells is given by

$$
\mathscr{P}=\sum_{p=1}^{N} \Sigma m_{\beta} \mathbf{f}_{\beta}^{(P)} \cdot \dot{\mathbf{x}}_{\beta}^{(P)} .
$$


The resultant applied force $m \mathbf{f}^{(\boldsymbol{P})}$ acting on the $P$ th. cell is given by

$$
m \mathbf{f}^{(P)}=\sum m_{\beta} \mathbf{f}_{\beta}^{(P)} .
$$

We define $\phi_{\beta}^{(P)}$ by

$$
\phi_{\beta}^{(P)}=\mathbf{f}_{\beta}^{(P)}-\mathbf{f}^{(P)} .
$$

Then

$$
\sum m_{\beta} \phi_{\beta}^{(P)}=0
$$

Introducing (5.6) and (5.10) into (5.8), and using (5.1), (5.7) and (5.11), we obtain

$$
\mathscr{P}=\sum_{P=1}^{N} m \mathbf{f}^{(P)} \cdot \dot{\mathbf{x}}^{(P)}+\sum_{P=1}^{N} \sum m_{\beta} \phi_{\beta}^{(P)} \cdot \dot{\xi}_{\beta}^{(P)} .
$$

The moment $\mathbf{M}_{\beta}^{(P)}$ of the applied force acting on the $\beta$ th. particle in the $P$ th. cell, about the fixed origin, is given by

$$
\mathbf{M}_{\beta}^{(P)}=m_{\beta} \mathbf{x}_{\beta}^{(P)} \times \mathbf{f}_{\beta}^{(P)} .
$$

With (5.6), (5.10), (5.7) and (5.11), it follows that the resultant moment $\mathbf{M}^{(P)}$ of the forces applied to the $P$ th. cell is given by

$$
\mathbf{M}^{(P)}=\sum \mathbf{M}_{\beta}^{(P)}=m \mathbf{x}^{(P)} \times \mathbf{f}^{(P)}+\sum m_{\beta} \xi_{\beta}^{(P)} \times \phi_{\beta}^{(P)} .
$$

\section{The deformation, forces and power}

Let $S$ be the boundary of the domain $\vec{V}$ occupied by the lattice of cells in the reference configuration. We now divide the domain $\bar{V}$ into an inner domain $V_{I}$ and a thin layer $V_{S}$ sitting at the boundary $\bar{S}$ of $\bar{V}$. We assume that the force applied to the $\beta$ th. particle of a cell varies slowly as we move from cell to neighboring cell in $V_{I}$. However, it may vary rapidly as we move from a cell in $V_{I}$ to a neighboring cell in $V_{S}$.

Let $S$ be a closed surface, which is piece-wise smooth and has slowly-varying curvature on some scale large compared with the cell dimensions, lying entirely in the closed domain $V_{I}$, but as close as possible to $V_{S}$. The surface $S$ will, in the continuum formulation, be the surface of the body considered in the reference configuration, and the domain $V$ bounded by $S$ will be the domain occupied by the body in the reference configuration. Let $V_{c}$ be the complement of $V$ in $\bar{V}$.

We define the partial density $\varrho_{\beta}$ of the $\beta$ th. mass points, in the reference configuration by

$$
\varrho_{\beta} v=m_{\beta},
$$

where $v$ is the volume of a cell in the reference configuration. The material density $\varrho$ of the body in the reference configuration is then given by

$$
\varrho=m / v=\sum \varrho_{\beta} .
$$


We define vector fields $\mathbf{x}(\mathbf{X}), \xi_{\beta}(\mathbf{X}), \mathbf{f}(\mathbf{X})$ and $\phi_{\beta}(\mathbf{X})$ over the domain $\bar{V}$ which satisfy the following conditions:

$$
\begin{gathered}
\int_{v_{P}} \mathbf{x} d \mathbf{X}=v \mathbf{x}^{(P)}, \quad \int_{v_{P}} \xi_{\beta} d \mathbf{X}=v \xi_{\beta}^{(P)}, \quad \sum \varrho_{\beta} \xi_{\beta}=0, \\
\int_{v_{P}} \varrho \mathbf{f} d \mathbf{X}=m \mathbf{f}^{(P)}, \\
\int_{\mathbf{v}_{P}} \varrho \phi_{\beta} d \mathbf{X}=m_{\beta} \boldsymbol{\phi}_{\beta}^{(P)}, \quad \sum \boldsymbol{\phi}_{\beta}=0, \\
\int_{v_{P}} \varrho\left\{\mathbf{x} \times \mathbf{f}+\sum \xi_{\beta} \times \phi_{\beta}\right\} d \mathbf{X}=m \mathbf{x}^{(P)} \times \mathbf{f}^{(P)}+\sum m_{\beta} \xi_{\beta}^{(P)} \times \phi_{\beta}^{(P)}, \\
\int_{\boldsymbol{v}_{\boldsymbol{P}}} \varrho\left\{\dot{\mathbf{x}} \cdot \mathbf{f}+\sum \dot{\xi}_{\beta} \cdot \boldsymbol{\phi}_{\beta}\right\} d \mathbf{X}=m \dot{\mathbf{x}}^{(P)} \cdot \mathbf{f}^{(P)}+\sum m_{\beta} \dot{\xi}_{\beta}^{(P)} \cdot \mathbf{f}_{\beta}^{(P)},
\end{gathered}
$$

where $v_{p}$ is the domain occupied by the $P$ th. cell in the reference configuration.

Equation (6.3) ${ }_{1}$ ensures that the average of the ordinary displacement field over a cell, in the continuum model, is equal to the displacement of the center of mass of the particles in the cell. Equations $(6.3)_{2}, 3$ ensure that the average of the $\beta$ th. director field $\xi_{\beta}$ over a cell gives the vector position of the $\beta$ th. particle in the cell, with respect to the center mass of the cell, and that the constraint condition (5.7) is satisfied. The condition (6.4) ensures that the resultant force acting on a cell is the same in the continuum and particle models. With (6.4), (6.1) and (6.2), the conditions (6.5) ensure that the resultant of the field $\varrho_{\beta} \mathbf{f}+\varrho \phi_{\beta}$ over the cell, in the continuum model, is equal to the force acting on the $\beta$ th. particle.

The condition (6.7) ensures that the power of the forces acting on a cell shall be the same in the continuum and particle models, if the force fields $\mathbf{f}$ and $\phi_{\beta}$, per unit mass of the continuum, are taken to be conjugate to the displacement fields $\mathbf{x}$ and $\xi_{\beta}$ respectively.

The condition (6.6) ensures that the resultant moment of the forces acting on a cell shall be the same in the continuum and particle models, if the moment, about the fixed origin, of the vectors $\mathbf{f}$ and $\phi_{\beta}$ are defined to be $\mathbf{x} \times \mathbf{f}$ and $\left(\mathbf{x}+\xi_{\beta}\right) \times \phi_{\beta}$ respectively.

We note that if we assume that the fields $x, \xi_{\beta}, \mathbf{f}$ and $\phi_{\beta}$ in (6.3)-(6.7) behave in the same way under superposed rigid motions of the body as do the fields $\mathbf{x}, \boldsymbol{\xi}_{\beta}$, $\mathbf{f}$ and $\phi_{\beta}$ introduced in Sect. 3, then the behavior of $\mathbf{x}^{(P)}, \xi_{\beta}^{(P)}, \mathbf{f}^{(P)}$ and $\phi_{\beta}^{(P)}$ implied by (6.3)-(6.7) is that which is appropriate to their physical meaning.

Let $\Delta V$ be the sub-domain of $V_{c}$ which sits on the element $\Delta S$ of the surface $S$. We assume that the dimensions of $\Delta S$ are large compared with those of a cell. We now define fields $\mathbf{F}$ and $\boldsymbol{\Phi}_{\beta}$ on $S$, such that

$$
\begin{gathered}
\int_{\Delta S} \mathbf{F} d \mathbf{X}=\int_{\Delta V} \varrho \mathbf{f} d \mathbf{X}, \\
\int_{\Delta S} \boldsymbol{\Phi}_{\beta} d \mathbf{X}=\int_{\Delta V} \varrho \boldsymbol{\phi}_{\beta} d \mathbf{X}, \quad \sum \boldsymbol{\Phi}_{\beta}=0, \\
\int_{\Delta S} \varrho\left\{\mathbf{x} \times \mathbf{F}+\sum \xi_{\beta} \times \boldsymbol{\Phi}_{\beta}\right\} d \mathbf{X}=\int_{\Delta V} \varrho\left\{\mathbf{x} \times \mathbf{f}+\sum \xi_{\beta} \times \phi_{\beta}\right\} d \mathbf{X},
\end{gathered}
$$




$$
\int_{\Delta S} \varrho\left\{\dot{\mathbf{x}} \cdot \mathbf{F}+\sum \dot{\xi}_{\beta} \cdot \boldsymbol{\Phi}_{\beta}\right\} d \mathbf{X}=\int_{\Delta V} \varrho\left\{\dot{\mathbf{x}} \cdot \mathbf{f}+\sum \dot{\xi}_{\beta} \cdot \boldsymbol{\phi}_{\beta}\right\} d \mathbf{X}
$$

We note that if we assume that the fields $\mathbf{F}$ and $\boldsymbol{\Phi}_{\beta}$ in (6.8)-(6.11) behave in the same way under superposed rigid motions of the body as do the fields $\mathbf{F}$ and $\boldsymbol{\Phi}_{\beta}$ introduced in $\S 3$, then equations (6.8)-(6.11) are consistent with the behavior of the fields $\mathbf{f}$ and $\boldsymbol{\phi}_{\beta}$ assumed in (6.4)-(6.7) and hence with their physical meaning in the particle model.

Using the relations (6.3)-(6.11), we obtain from (5.12) the following expression for the power $\mathscr{P}$ of the forces applied to the body:

$$
\mathscr{P}=\int_{V} \varrho\left(\dot{\mathbf{x}} \cdot \mathbf{f}+\sum \dot{\boldsymbol{\xi}}_{\beta} \cdot \boldsymbol{\phi}_{\beta}\right) d V+\int_{S}\left(\dot{\mathbf{x}} \cdot \mathbf{F}+\sum \dot{\boldsymbol{\xi}}_{\beta} \cdot \boldsymbol{\Phi}_{\beta}\right) d S .
$$

This is the expression which underlies the analysis in Secs. 3 and 4.

\section{The specific internal energy and heat flux}

Having given physical meaning, in terms of the particle model, to the ordinary and director body and surface forces, we must now give physical meaning to the other quantities - the specific internal energy $\varepsilon$, the specific entropy $\eta$, the absolute temperature $T$, the specific Helmholtz free energy $w$, and the heat flux fields $q$ and $Q$ - which occur in the continuum theory developed in Secs. 3 and 4. However, unlike the ordinary and director deformation, body force and surface force fields, these have no counterparts in the particle model when it is discussed on a cell-by-cell basis.

We can, however, give them physical meaning in the particle model in the following manner. The internal energy of an aggregate of cells is the sum of the kinetic energies of the particles in them and the potential energy due to the interaction of these particles. There is also an interaction energy associated with the forces between the particles in this aggregate and the remainder of the body. For the purpose of our discussion, we shall assume that this interaction energy is small for particles which are separated by distances large compared with the cell dimensions. Then, provided that the aggregate of cells considered has dimensions sufficiently large compared with those of a single cell, we can neglect the energy of interaction of the aggregate with the remainder of the body. Now, provided that the aggregate of cells is thermomechanically almost homogeneous $\left({ }^{2}\right)$, on some scale which is large compared with the cell dimensions, we can replace the total internal energy of the aggregate by the integral over the mass of the aggregate, of a specific internal energy, which is a scalar field.

Similar considerations enable us to replace the total flux of heat entering the aggregate

${ }^{2}{ }^{2}$ We consider that an aggregate of cells is thermomechanically homogeneous, if all of the following conditions are satisfied:

(i) $\xi_{\beta}(\beta=1, \ldots, \nu)$ is independent of the cell chosen;

(ii) $\left(\mathbf{x}^{(P)}-\mathbf{x}^{(Q)}\right)-\left(\mathbf{X}^{(P)}-\mathbf{X}^{(Q)}\right)$ is independent of $P$ and $Q$ for pairs of cells which are similarly located with respect to each other, in the reference configuration;

(iii) the time average of the kinetic energy, due to thermal motion, of the $\beta$ th. particle is independent of the cell chosen, for $\beta=1, \ldots, v$. 
of cells, otherwise than through its boundary, by the integral over the mass of the aggregate of a scalar heat flux field $q$. Since we are restricting our discussion to processes which are thermomechanically nearly homogeneous, on some scale which is large compared with the cell dimensions, identification of the absolute temperature $T$ presents no problem. Then, from (4.2) and (4.5), we have definitions of the specific entropy and specific Helmholtz free energy.

The surface heat flux $Q$ of the continuum formulation can also be identified in the particle model. We consider the subdomain $\Delta V$ of $V_{c}$ which sits on the element of area $\Delta S$ of the surface $S$. Then $\int_{\Delta S} Q d \mathbf{X}$ is the rate at which heat enters $\Delta V$, i.e. the rate at which the total kinetic and potential energy of $\Delta V$ increases (neglecting the potential energy of interaction of the particles in $\Delta V$ with those outside $\Delta V$ ) minus the power of the applied forces acting on the particles in $\Delta V$ and of the forces on these particles due to their interaction with particles outside $\Delta V$. In order that this heat flux shall be expressible as the surface integral of a scalar field, it is necessary that the process considered be thermomechanically nearly homogeneous on some scale which is large compared with the cell dimensions, as we move over the surface $S$. We note that the concept of thermomechanical homogeneity involved here is somewhat different from that used in discussing the body fields. Here homogeneity is required only as we move parallel to $S$, while inhomogeneity is allowable in a direction normal to $S$. (In this definition of $Q$, we neglect the small heat flux due to the possible passage of energy into $\Delta V$ through its periphery. If we took this into account, we would have to introduce, in the continuum model, a heat flux field in the surface, measured per unit length in the surface.)

The total kinetic and potential energy of $\Delta V$ (neglecting the potential energy of interaction of the particles in $\Delta V$ with those outside $\Delta V$ ) becomes, in the continuum formulation, the surface energy $E$, per unit area, associated with the surface element $\Delta S$. This is usually negligible for solids.

We have already shown how the expression (6.12) used in the continuum formulation for the power of the applied forces can be given meaning in terms of the particle model. With the meanings given to $\varepsilon, q$ and $Q$ in this section, we can now obtain the global energy balance equation (3.4). This equation may, of course, be applied to any portion of the body, with the assumption, which has already been made, that the interactions between the various portions of the body are short range interactions and the dimensions of the domain considered are large enough to validate the separation of the domain into a "surface" and an interior. We are therefore limited to applying equation (3.4) to portions of a body, whose dimensions are large compared with those of a single cell.

It follows that in the argument leading to equations (3.5) and (3.6), we cannot make the dimensions of the elementary volume considered vanishingly small. However, we can still arrive at these equations provided that the process considered is thermomechanically nearly homogeneous over the portion of the body considered.

The remainder of the discussion of Sect. 3 and 4 then follows without the necessity for further consideration of the particle model to give it validity.

We can gain some insight into the meaning, in terms of the particle model, of the assumption $(4.1)_{1}$, which is made in the continuum formulation, that the specific internal 
energy $\varepsilon$ depends on $x_{j, B}, \xi_{j}^{(\beta)}, \xi_{j, B}^{(\beta)}$, from the following considerations. We assume that the fields $\mathbf{x}$ and $\xi^{(\beta)}$ vary sufficiently slowly as we pass from cell to neighboring cell that we can make the approximation

$$
\begin{aligned}
& x_{j}(\mathbf{X}+\alpha) \approx x_{j}(\mathbf{X})+\alpha_{B} x_{j, B}(\mathbf{X}), \\
& \xi_{j}^{(\beta)}(\mathbf{X}+\alpha) \approx \xi_{j}^{(\beta)}(\mathbf{X})+\alpha_{B} \xi_{j, B}^{(\beta)}(\mathbf{X}),
\end{aligned}
$$

where $\alpha$ is the translation vector which, in the reference configuration, brings a cell, say the $P$ th. cell, into coincidence with a neighboring cell, say the $Q$ th. cell. Then, from (6.3),

$$
\begin{aligned}
x_{i}^{(Q)}-x_{i}^{(P)} & =\frac{1}{v} \int_{v_{P}} \alpha_{B} x_{i, B}(\mathbf{X}) d \mathbf{X}, \\
\left(\xi_{\beta}^{(Q)}-\xi_{\beta}^{(P)}\right)_{i} & =\frac{1}{v} \int_{v_{P}} \alpha_{B} \xi_{i, B}^{(\beta)}(\mathbf{X}) d \mathbf{X} .
\end{aligned}
$$

It is then evident that provided that $\mathbf{x}(\mathbf{X})$ and $\xi_{\beta}(\mathbf{X})$ vary sufficiently smoothly and slowly as we pass from cell to neighboring cell, the dependence of $\varepsilon$ on $x_{j, B}$ and $\xi_{j, B}^{(\beta)}$ implies that, in the particle model, $\varepsilon$ depends on the relative displacements of the particles in one cell with respect to those in neighboring cells. (Indeed, if the continuum theory developed in $\S 4$ is to model the particle system considered in this section, it would seem appropriate to restrict the dependence of $\varepsilon$ on $x_{j, B}, \xi_{j, B}^{(\beta)}$, and $\xi_{j}^{(\beta)}$ to dependence on $x_{j, B}+$ $+\xi_{j, B}^{(\beta)}$ and $\xi_{j}^{(\beta)}$.) The dependence of $\varepsilon$ on $\xi_{j}^{(\beta)}$ implies that $\varepsilon$ also depends on the displacements of the particles in the individual cells with respect to their centers of mass.

\section{Acknowledgment}

The research described in this paper was supported by a grant from the National Science Foundation to Lehigh University.

\section{References}

1. H. F. Tiersten and J. L. Bleustein, R.D. Mindlin and Applied Mechanics, ed. G. Herrmann, Pergamon Press, New York 1974.

2. A. E. Green and R.S. Riviln, Arch. Rat'l Mech. Anal., 17, 113, 1964.

3. A. E. Green and R. S. Rivlin, Proc. IUTAM Symposium Vienna 1966, ed. H. Parkus and L. I. SEDov; Springer, Vienna 1967.

4. R.S. RIVLIN, Mechanics of generalized continua, Proc. IUTAM Symposiun Freudenstadt-Stuttgart 1967, ed. E. KRÖNER; Springer, Berlin 1968.

5. R. S. Rivlin, Istituto Naz. di Alta Matematica, Symposia Mathematica, 1, 3571968. 